\title{
Educational design research: Signs of progress
}

\author{
Thomas C. Reeves \\ University of Georgia
}

This special issue of the Australasian Journal of Educational Technology includes an introductory article by the guest editors and six papers that illustrate the potential of educational design research (EDR) to address important problems in higher education. In this final paper, reflections on the papers are made. Then the rationale for conducting EDR instead of media comparison studies is described with a concrete example. This paper concludes with a proposal for expanding educational design research through the establishment of consortia of collaborating researchers, practitioners, and funding agencies focused on the most salient challenges faced in education today.

\section{Introduction}

The editors of this special issue of the Australasian Journal of Educational Technology set forth an ambitious goal of "showcasing exemplars of high quality design-oriented research in technology-supported postsecondary educational settings" to advance the state-of-the-art of educational design research (EDR) (Kopcha, Schmidt, \& McKenney, 2015, p.iii). To the credit of the editors and the authors of the six papers in this special issue, this goal has been largely attained.

\section{Reflections on the paper set}

In the first paper, Bollen, van der Meij, Leemkuil, and McKenney (2015) present a detailed description of the application of EDR to the problem of providing support to undergraduate students engaged in learning by designing (LBD) (Kafai \& Resnick, 1996). One of the most challenging aspects of this problem is finding the appropriate level of support for this constructivist pedagogical approach. If too little support for LBD is provided, students will flounder or fall back on inappropriate strategies such as divide and conquer cooperative learning instead of the much more desirable strategy of cooperative learning whereby learners engage in authentic teamwork. If too much performance support is provided, students simply follow the guidance step-by-step like a recipe, and ultimately fail to learn by designing.

The Bollen et al. (2015) paper focuses primarily on the Design and Construction phase of the McKenney and Reeves (2012) generic model of educational design research as illustrated in Figure 1 of the introductory paper of this special issue by Kopcha, Schmidt, and McKenney (2015). In addition to a promising intervention to support students engaged in LBD, three reusable design principles emerged from the study. Having been involved in a number of projects focused on developing electronic performance support systems (EPSS) for companies like Apple and NCR during my career (e.g., Gustafson \& Reeves, 1990; Jury \& Reeves, 1999), all three principles strike me as valid and widely applicable. This paper clearly demonstrates the dual outcomes of EDR.

In the second paper, Lakkala, Toom, Ilomäki, and Muukkonen (2015) address the serious problem of the gap between the needs of society and the outcomes of undergraduate higher education (Arum \& Roksa, 2011). Whereas design principles emerged from the Bollen et al. (2015) EDR, the Lakkala et al. (2015) EDR initiative began with a predefined set of design principles and investigated the results of redesigning three undergraduate level courses based upon these principles. The six principles are grounded in the trialogical approach to learning defined by Paavola and Hakkarainen (2005) as a constructivist pedagogical model that seeks to engage students in individual and collective knowledge acquisition through collaborative participation in the design and development of shared objects that have real world relevance.

The Lakkala et al. (2015) paper focuses primarily on the Evaluation and Reflection phase of the McKenney and Reeves (2012) generic EDR model. Although only one iteration of formative evaluation is reported in the 
paper, the study illustrates the potential of the design principles inherent in Paavola and Hakkarainen (2005) trialogical approach to learning to guide curricular reform in undergraduate higher education courses so that they better address the generic work-related competencies that graduates will need to survive in an increasingly competitive work environment (Ford, 2015). The kind of radical redesign of the undergraduate curriculum that many view as necessary (Carey, 2015; Christensen \& Eyring, 2011; Ford, 2015; Healey \& Jenkins, 2009) may be forced upon institutions of higher education by external pressures, but I believe any reform efforts are much more likely to be successful if they are guided by the kind of EDR described in the Lakkala et al. (2015) paper.

In the third paper, Er, Kopcha, Orey, and Dustman (2015) tackle the complex task of providing support for students seeking help in a large-enrollment science course that utilises a flipped classroom pedagogical model (Herreid \& Schiller, 2013). The topic of the science course, microbiology, certainly appears to be one that is challenging enough for most undergraduate students that help seeking would be an important behavior to encourage and enable. This study highlights two of the important aspects that should drive any EDR agenda, first, a focus on a significant pedagogical problem, and second, close collaboration among researchers and practitioners.

The Er et al. (2015) paper reports primarily on the Evaluation and Reflection phase of the McKenney and Reeves (2012) generic EDR model. The paper includes the findings and design implications of one initial micro-cycle and three meso-cycles of data collection and refinement of EchoLu, an online tool for supporting help seeking that integrates features based upon four help-seeking design principles initially derived from traditional classroom instruction (Karabenick, 1998). The heart of the paper focuses on the last two iterations during which EchoLu was systematically evaluated and improved over the course of two sequential twomonth long meso-cycles. In addition to providing the guidance needed for improving the EchoLu tool, these two cycles yielded new insight into the design principles driving the design and construction of EchoLu, and even yielded a novel design principle focused on information seeking as distinct from help seeking.

In the fourth paper, Curwood, Tomitsch, Thomson, and Hendry (2015) describe the application of EDR to assist academic staff in using student evaluation of teaching (SET) data to improve teaching and learning. Their particular focus is on alternative approaches to assessment as the designers and the faculty participants in the study shared the view that assessment is the key pedagogical dimension of instruction that drives student learning.

The Curwood et al. (2015) paper encompasses all phases of the McKenney and Reeves (2012) generic EDR model. The intervention developed by this EDR initiative is Ask Charlie, an online resource that presents academic staff with personal recommendations for teaching resources tailored to factors such as class size, discipline, and assessment modes as well as personalised SET data. Ask Charlie (http://www.askcharlie.co/) includes a number of ways of viewing and interpreting SET data, case studies of how others are using such data, video testimonials featuring actual faculty members from the university where the EDR has been carried out, and other features. One of the more interesting ideas in the paper is the distinction the authors made between the features the designers built into the Ask Charlie website, and the affordances that academic staff actually perceived and accessed.

In the fifth paper, Thompson Long and Hall (2015) take on the difficult problem of helping novice teachers learn to engage in reflective practice. The intervention they investigated involves digital storytelling using low threshold applications of information and communications technologies (ICTs) guided by a refined theoretical framework called R-NEST (reflection, narrative, engagement, sociality, and technology).

The Thompson Long and Hall (2015) paper also describes all phases of the McKenney and Reeves (2012) generic EDR model. The authors make excellent use of graphics to illustrate the EDR process over several years. It is to the credit of these design researchers that the resultant innovation has now become an integral component of a large-scale teacher preparation masters program. This paper is derived from a longer, more detailed report of Thompson Long's (2014) doctoral dissertation. Thompson Long's dissertation provides an 
excellent model for other graduate students considered engaging in EDR during their doctoral studies.

In the sixth and last paper, Wozniak (2015) focuses EDR on the problem of helping people in the health professions transition from traditional academic environments to online learning at a distance. Learning to learn online is a challenge for most people, but especially for mature adults returning to university programs while trying to balance studying with the heavy demands of their jobs, families, and other obligations (Simpson, 2012).

The Wozniak (2015) paper is unique in that in addition to presenting findings related to all phases of the McKenney and Reeves (2012) generic EDR model, it expands our understanding of that model by incorporating conjecture mapping (Sandoval, 2014) into it. This paper is also unusual in that it describes how a multi-year EDR project was extended across 5 years to two different academic contexts. Although this EDR initiative did yield a practical intervention in the form of an online orientation resource, the more significant outcomes appear to be the refined theoretical knowledge and design principles for helping health professionals transition to online learning. This is no small accomplishment. Ideally, EDR leads to the generation of refined theory for design and action in forms ranging from general guidelines to explicit prescriptions for how to design and implement an intervention (Gregor, 2006). The design principles emerging from Wozniak's (2015) paper are not so general as to be difficult to apply, nor too explicit so as to limit their applicability to specific contexts.

\section{How might this paper set inform others?}

The papers in this special issue provide a refreshing and urgently needed departure from mainstream educational technology literature. For nearly a half century, various scholars have issued calls for a reorientation of educational technology research away from simplistic media comparison studies toward studies that are more relevant to the real world problems faced by educational practitioners (Clark, 1983; Kozma, 2000; Mielke, 1968; Oliver, 2011; Salomon, 1991). One might expect that media comparison studies would be a thing of the past. But that is not the case.

The urgency of this issue struck me, as the latest edition of EDUCAUSE Review arrived while I was reviewing this paper set. EDUCAUSE Review is a bimonthly publication targeted at the higher education information technology community that has both a print version and an open-access digital version available at: http://er.educause.edu/. This award-winning journal includes peer-reviewed articles as well as columns and case studies replete with practical advice related to IT in higher education.

An article titled "Paper or tablet? Reading recall and comprehension" appears in the most recent digital version of EDUCAUSE Review (Niccoli, 2015). The brief abstract for the article states:

What effect do digital devices have on our digital brains? To uncover the influence on learning of using digital tablets for reading, the Coast Guard Leadership Development Center conducted an experiment to ascertain differences in recall and comprehension between tablet and paper readers.

This is a classic example of the type of media comparison research that continues to be conducted despite the fact that the results are almost always the same: no significant differences. For this experiment, 231 senior leadership students at the US Coast Guard Leadership Development Center were randomly assigned to either a digital tablet version (119 students) or a paper version (112 students) of the same 800 word leadership article. These students are non-commissioned members of the Coast Guard with approximately 8 years of professional experience. The time-on-task for this experiment is not reported, but given that adults read about 200 words per minute (Noyes \& Garland, 2008), the treatment was unlikely to have lasted more than 10 minutes. After reading the two-page long article, students were given an assessment with 10 multiple-choice items to measure recall accuracy and two short essay questions to measure comprehension. There is no indication regarding how long students had to complete this assessment, nor is there any discussion about how 
well this brief article was aligned with the goals of the course in which the students were enrolled other than that the article concerned leadership.

As should have been predicted based on the relevant literature, no significant differences were found related to either recall or comprehension despite the relatively large sample size not often found in these types of studies. The author did report a pattern of greater frequencies of higher scores for paper readers than among digital readers, but the implications of this finding are unclear. The author reported repeating the experiment with another sample of 205 students, but again found no significant differences in recall or comprehension. This specific study is not the problem. For this kind of media comparison research, this experiment was reasonably well done and reported, although more information about time-on-task and the motivation of the students to read the leadership paper would be helpful.

\section{What could feed real progress?}

So what was the urgency that struck me? And how might educational design researchers approach redesigning Niccoli's (2015) study? Regarding the first question, studies of this kind that seek to determine what works better, e.g., a technological innovation (reading on an iPad screen) or a traditional medium (reading a paper text), do not begin to grapple with the complexity of the variables involved in learning. Experimental studies focusing so exclusively on tools or media, and not on the people using them or their contexts, may easily lend themselves to execution and reporting. Yet such studies offer little to the body of practical knowledge about teaching and learning, as Stanford University Professor Emeritus D. C. Phillips (2015) explained:

Learning is a phenomenon that involves real people who live in real, complex social contexts from which they cannot be abstracted in any meaningful way. Difficult as it is for researchers to deal with (especially if they are suffering from physics envy), learners are contextualized. They do have a gender, a sexual orientation, a socioeconomic status, an ethnicity, a home culture; they have interests - and things that bore them; they have or have not consumed breakfast; and they live in neighborhoods with or without frequent gun violence or earthquakes, they are attracted by (or clash with) the personality of their teacher, and so on. It probably is the case, as some physical scientists have noted, that in a mature field of research, like physics, "it is obvious which variables are important and how to control them"; the problem is that in education, just about all the variables are relevant, and controlling them (even if possible let alone desirable) yields results that are difficult or impossible to generalize to the other almost infinite number of settings where these variables do, indeed, vary. (pp. 10-11)

Regarding the second question about how educational design researchers would redesign Niccoli's (2015) study, they would surely want to know much more about the context. What are the goals and objectives of the Leadership Development Program (LDP) in which these students are enrolled at the US Coast Guard Academy? How are the pedagogical designs of the LDP courses aligned with these goals and objectives and with the ways that is learning assessed? What are the strengths and weaknesses of the LDP in the eyes of various stakeholders, for example, students, instructors, and commanders?

First and foremost, educational design researchers working with practitioners (e.g., the LDP instructors) would seek to identify the kinds of significant problems that students and practitioners are confronting regarding the role of reading in this program. Perhaps the students simply are not doing the readings because they perceive them as unaligned with the ways that their knowledge and skills will be assessed. Or perhaps the students read the texts, but fail to see any relevance of the readings to their studies. Alternatively, there may be no problems detected with the readings in this program, but problems with other aspects of the program may be revealed. Addressing these types of questions and reviewing relevant literature in search of relevant design principles would also be integral during the Analysis and Exploration phase of an EDR study.

Once a thorough understanding of the problems in the LDP has been attained, the educational design researchers would work closely with practitioners and other experts to develop a prototype solution to these 
problems, guided by the design principles emerging from the literature review, consultation with various types of experts, and identifying best practices. That prototype solution may or may not involve a technology component like an iPad. Text in print and text on screens have very different affordances. Suppose one of the most important goals of the LDP concerns how to handle dangerous refugee situations on the high seas, for example, when to remove passengers from an overcrowded vessel versus towing the vessel to shore. Reading a print text might be relevant, but a digital text that included videos of real case studies and even interactive simulations might be much more relevant and effective. The nature of the prototype solution would depend on a variety of important variables, not simply whether printed text is read on paper or a screen.

Once a prototype solution is crafted, multiple methods would be used to refine both the prototype intervention and the design principles inherent in it during the Evaluation and Reflection phase of EDR. One method might be a quasi-experimental design to test specific features of the prototype solution. Educational design researchers do not disparage experimental methods or any other research methods. They view all research methods as tools and identify methodological fit for purpose. Educational design researchers would not end their study when the perfect solution is developed because they understand that as one problem is addressed others will inevitably emerge. Of course, they may well move away from a particular line of inquiry once a viable solution is achieved and the researchers and practitioners agree that it is time to move on to other issues.

With the all too often repeated media comparison studies, no significant differences is a common result, or alternatively, numerous studies that have conflicting results (Clark, 1983). EDR, on the other hand, has the potential to enable educationally significant differences through the development and refinement of robust interventions while at the same time yielding reusable design principles (McKenney \& Reeves, 2013). Simply put, EDR is a win-win proposition.

\section{The importance of shared agendas}

As described above, EDR has the potential to help researchers contribute to meaningful progress by tackling real problems while maintaining a strong focus on teaching and learning processes alongside, not usurped by, innovative tools and approaches to facilitate or extend those processes. All six of the papers in this special issue make noteworthy contributions to our understanding of EDR, and provide valuable exemplars for other educational researchers who may wish to become more involved in design research. The problems they address, although all situated within higher education, are very diverse in nature, including:

- providing support to undergraduate students engaged in learning by designing,

- improving the extent to which the outcomes of undergraduate higher education serve the needs of society,

- supporting students as they seek help in a large-enrollment science course that utilises a flipped classroom design,

- enabling academic staff to more effectively use student evaluation of teaching data to improve teaching and learning,

- helping novice teachers learn to become reflective practitioners, and

- helping health professionals transition to online learning.

The diversity of these problems is appropriate in a special journal issue of this kind. However, I am increasingly concerned that there is a lack of synergy across the community of EDR researchers around the world. There are many different academic conferences where researchers with EDR goals can present their work (e.g., the annual Australasian Society for Computers in Learning in Tertiary Education (ASCILITE) conference) and various journals where they might publish their papers (e.g., the Australasian Journal of Educational Technology (AJET) in which these papers appear). At such a conference or within an annual volume of a journal, researchers with design/development goals may well encounter one or several scholars addressing the same or a closely related problem and exchange ideas to their mutual benefit. But there is a need for something more. 
Although I am encouraged by the increasing interest in EDR, I fear that there are too many isolated agendas focused on a large number of esoteric problems, and that in the end, little progress will be made to confront the larger scale problems in education. Tett (2015) reminds us that people in organisations often unwittingly organise themselves into silos that stifle collaboration across artificial barriers and ultimately limit innovation. A first step in avoiding the silo effect among educational technology researchers could be establishing an evolving repository of meaningful problems on which the educational technology research community could focus their EDR agendas in collaboration with other researchers as well as practitioners in universities, schools, businesses, and the like. Models for such a repository of high-level research goals exist in other fields such as the human genome project (McElheny, 2012) and the scientific investigation of high-energy particle physics (Boisot, Nordberg, Yami, \& Nicquevert, 2011) as well as in the public policy sector (United Nations, 2000). For example, the United Nations Millennium Development Goals established in 2000 were exceptionally ambitious to:

1. eradicate extreme poverty and hunger,

2. achieve universal primary education,

3. promote gender equality,

4. reduce child mortality,

5. improve maternal health,

6. combat HIV/AIDS, malaria, and other diseases,

7. ensure environmental sustainability, and

8. develop a global partnership for development.

These goals were to be reached by 2015, but to no one's surprise, none of them were completely attained. Nonetheless, Tony Blair (2015), former Prime Minister of the United Kingdom, recently proclaimed "huge progress was made: Hundreds of millions of people have been lifted out of poverty, maternal mortality has been reduced by almost half and millions more children are now in school." Convinced that the Millennium Development Goals had helped guide this kind of progress, the United Nations recently established a new set of 17 Sustainable Development Goals intended to lower global poverty, hunger, and inequality while also addressing environmental challenges (Waage et al., 2015).

Could the educational technology community establish a set of ambitious goals to be addressed by consortia of scholars using a variety of research approaches, including EDR? It would be a bold undertaking, but perhaps a professional organisation like ASCILITE could convene a panel of educational technology researchers to collaborate with representative practitioners to establish a set of high-level goals related to learning, teaching, and performance that would be addressed over the next 25 years. As noted above, the six papers in this special issue represent interventions that are widely divergent. These interventions can be divided into two groups: four focused on supporting learners and two focused on the needs of teachers. At this early stage of the uptake of EDR, this is to be expected. But consortia of collaborating researchers, practitioners, and funding agencies focused on the most salient problems facing education may realise much greater impact. It is a collective enterprise worth considering.

\section{Final words}

Educational design research provides an exceptionally suitable approach to systematic inquiry in the field of educational technology that maximises both rigor and relevance (McKenney \& Reeves, 2012; Reeves, 2011). Over the past few years, the Australasian Journal of Educational Technology has been providing an outlet for EDR studies (e.g., Drexler, 2010; Swann, 2010; Tee \& Lee, 2011). The editors of this special issue and I are not alone in seeing this as an encouraging sign of progress. Scanlan (2015) compared this still emerging research genre to the evidence-based medicine movement, and wrote, "[Design-based research] DBR reflects a paradigm shift in generating evidence-based claims in education.” This special issue marks an important step forward that will hopefully encourage a new generation of educational technology researchers to rise up to the challenge of pursuing research agendas that address real problems, in ways that are both rigorous and relevant. 


\section{References}

Arum, R., \& Roksa, J. (2011). Academically adrift: Limited learning on college campuses. Chicago, IL: University of Chicago Press.

Blair, T. (2015). Huge progress made in millennium development goals. Gulf News. Retrieved from http:/gulfnews.com/opinion/thinkers/huge-progress-made-in-millennium-development-goals-1.1593876

Boisot, M., Nordberg, M., Yami, S., \& Nicquevert, B. (2011). Collisions and collaboration: The organization of learning in the ATLAS experiment at the LHC. Oxford: Oxford University Press.

Bollen, L., van der Meij, H., Leemkuil, H. H., \& McKenney, S. E. (2015). In search of design principles for developing digital learning \& performance support for a student design task. Australasian Journal of Educational Technology, 31(5), 500-520.

Carey, K. (2015). The end of college: Creating the future of learning and the university of everywhere. New York, NY: Penguin Group.

Christensen, C. M., \& Eyring, H. J. (2011). The innovative university: Changing the DNA of higher education from the inside out. San Francisco, CA: Jossey-Bass.

Clark, R. E. (1983). Reconsidering research on learning from media. Review of Educational Research, 53(4), 445-459. doi:10.3102/00346543053004445

Curwood, J. S., Tomitsch, M., Thomson, K., \& Hendry, G. D. (2015). Professional learning in higher education: Understanding how academics interpret student feedback and access resources to improve their teaching. Australasian Journal of Educational Technology, 31(5), 556-571.

Drexler, W. (2010). The networked student model for construction of personal learning environments: Balancing teacher control and student autonomy. Australasian Journal of Educational Technology, 26(3), 369-385. Retrieved from http://ajet.org.au/index.php/AJET/article/view/1081

Er, E., Kopcha, T. J., Orey, M., \& Dustman, W. (2015). Exploring college students’ online help-seeking behavior in a flipped classroom with a web-based help-seeking tool. Australasian Journal of Educational Technology, 31(5), 537-555.

Ford, M. (2015). Rise of the robots: Technology and the threat of a jobless future. New York, NY: Basic Books.

Gregor, S. (2006). The nature of theory in information systems. MIS Quarterly, 30(3), 611-642.

Gustafson, K. L., \& Reeves, T. C. (1990). IDioM: A platform for a course development expert system. Educational Technology, 30(3), 19-25.

Healey, M., \& Jenkins, A. (2009). Developing undergraduate research and inquiry. York: The Higher Education Academy. Retrieved from https:/www.heacademy.ac.uk/resource/developing-undergraduateresearch-and-inquiry

Herreid, C. F., \& Schiller, N. A. (2013). Case studies and the flipped classroom. Journal of College Science Teaching, 42(5), 62-66.

Jury, T., \& Reeves, T. C. (1999). An EPSS for instructional design: NCR's quality information products process. In J. van den Akker, R. Branch, K. Gustafson, N. Nieveen, \& T. Plomp (Eds.), Design approaches and tools in education and training (pp. 183-194). Dordrecht: Kluwer Academic Publishers.

Kafai, Y. B., \& Resnick, M. (1996). Constructionism in practice: Designing, thinking, and learning in a digital world. Mahwah, NJ: Lawrence Erlbaum Associates.

Karabenick, S. A. (1998). Strategic help seeking: Implications for learning and teaching. Mahwah, NJ: Lawrence Erlbaum Associates.

Kopcha, T. J., Schmidt, M., \& McKenney, S. E. (2015). Educational design research (EDR) in post-secondary learning environments. Australasian Journal of Educational Technology, 31(5), i-ix.

Kozma, R. (2000). Reflections on the state of educational technology research and development. Educational Technology Research and Development, 48(1), 5-15. doi:10.1007/BF02313481

Lakkala, M., Toom, A., Ilomäki, L, \& Muukkonen, H. (2015). Re-designing university courses to support collaborative knowledge creation practices. Australasian Journal of Educational Technology, 31(5), 521536.

McElheny, V. K. (2012). Drawing the map of life: Inside the human genome project. New York, NY: Basic Books. 
McKenney, S. E., \& Reeves, T. C. (2012). Conducting educational design research. New York, NY: Routledge.

McKenney, S. E., \& Reeves, T. C. (2013). Systematic review of design-based research progress: Is a little knowledge a dangerous thing? Educational Researcher, 42(2), 97-100. doi:10.3102/0013189X12463781

Mielke, K. W. (1968). Questioning the questions of ETV research. Educational Broadcasting, 2, 6-15.

Niccoli, A. (2015). Paper or tablet? Reading recall and comprehension. EDUCAUSE Review. Retrieved from http://er.educause.edu/articles/2015/9/paper-or-tablet-reading-recall-and-comprehension

Noyes, J. M., \& Garland, K. J. (2008). Computer-vs. paper-based tasks: Are they equivalent? Ergonomics, 51(9), 1352-1375. doi:10.1080/00140130802170387

Oliver, M. (2011). Technological determinism in educational technology research: Some alternative ways of thinking about the relationship between learning and technology. Journal of Computer Assisted Learning, 27(5), 373-384. doi:10.1111/j.1365-2729.2011.00406.x

Paavola, S., \& Hakkarainen, K. (2005). The knowledge creation metaphor - An emergent epistemological approach to learning. Science \& Education, 14(6), 535-557. doi:10.1007/s11191-004-5157-0

Phillips, D. C. (2014). Research in the hard sciences, and in very hard "softer" domains. Educational Researcher, 43(1), 9-11. doi:10.3102/0013189X13520293

Reeves, T. C. (2011). Can educational research be both rigorous and relevant? Educational Designer, 1(4). Retrieved from http://www.educationaldesigner.org/ed/volume1/issue4/article13/

Salomon, G. (1991). Transcending the qualitative-quantitative debate: The analytic and systemic approaches to educational research. Educational Researcher, 20(6), 10-18. doi:10.3102/0013189X020006010

Sandoval, W. (2014). Conjecture mapping: An approach to systematic educational design research. Journal of the Learning Sciences, 23(1), 18-36. doi:10.1080/10508406.2013.778204

Scanlan, M. (2015). Paradigm shift happens. Teachers College Record. Retrieved from http://www.tcrecord.org/Content.asp?ContentID=18137

Simpson, O. (2012). Supporting students for success in online and distance education (3rd ed.). New York, NY: Routledge.

Swann, J. (2010). A dialogic approach to online facilitation. Australasian Journal of Educational Technology, 26(1), 50-62. Retrieved from http://ajet.org.au/index.php/AJET/article/view/1102

Tee, M. Y., \& Lee, S. S. (2011). From socialisation to internalisation: Cultivating technological pedagogical content knowledge through problem-based learning. Australasian Journal of Educational Technology, 27(1), 89-104. Retrieved from http://ajet.org.au/index.php/AJET/issue/view/19

Tett, G. (2015). The silo effect: The peril of expertise and the promise of breaking down barriers. New York, NY: Simon \& Schuster.

Thompson Long, B. (2014). Designing digital storytelling: Creative technology for reflection in initial teacher education (Doctoral dissertation). School of Education, National University of Ireland, Galway, Ireland. Retrieved from http://rian.ie/en/item/redirect/record_id/97674

Thompson Long, B., \& Hall, T. (2015). R-NEST: Design-based research for technology-enhanced reflective practice in initial teacher education. Australasian Journal of Educational Technology, 31(5), 572-596.

United Nations. (2000). United Nations Millennium Declaration. A/55/L.2. Retrieved from http://www.un.org/millennium/declaration/ares552e.htm

Waage, J., Yap, C., Bell, S., Levy, C., Mace, G., Pegram, T., ... \& Poole, N. (2015). Governing the UN sustainable development goals: Interactions, infrastructures, and institutions. The Lancet Global Health, 3(5), e251-e252. doi:10.1016/S2214-109X(15)70112-9

Wozniak, H. (2015). Conjecture mapping to optimize the educational design research process. Australasian Journal of Educational Technology, 31(5), 597-612.

Corresponding author: Thomas C. Reeves; treeves@uga.edu

Australasian Journal of Educational Technology (C) 2015.

Please cite as: Reeves, T. C. (2015). Educational design research: Signs of progress. Australasian Journal of Educational Technology, 31(5), 613-620. 